This document is confidential and is proprietary to the American Chemical Society and its authors. Do not copy or disclose without written permission. If you have received this item in error, notify the sender and delete all copies.

\title{
Start-up of electromethanogenic microbial electrolysis cells with two different biomass inocula for biogas upgrading
}

\begin{tabular}{|r|l|}
\hline Journal: & ACS Sustainable Chemistry \& Engineering \\
\hline Manuscript ID & sc-2017-01636f.R1 \\
\hline Manuscript Type: & Article \\
\hline Date Submitted by the Author: & 30-Jul-2017 \\
\hline Complete List of Authors: & $\begin{array}{l}\text { Cerrillo, Miriam; IRTA, GIRO } \\
\text { Viñas, Marc; IRTA, GIRO } \\
\text { Bonmatí, August; IRTA, GIRO }\end{array}$ \\
\hline
\end{tabular}

SCHOLARONE ${ }^{\text {m }}$

Manuscripts 


\title{
Start-up of electromethanogenic microbial
}

\section{electrolysis cells with two different biomass inocula for biogas upgrading}

\author{
Míriam Cerrillo, Marc Viñas, August Bonmati* \\ IRTA. GIRO Joint Research Unit IRTA-UPC. Torre Marimon, s/n. E-08140, Caldes de Montbui, \\ Barcelona (Spain). \\ * E-mail: august.bonmati@irta.cat
}

\begin{abstract}
The performance and biomass enrichment of the biocathode of a pair of lab-scale two-chambered microbial electrolysis cells (MEC) were assessed for 95 days as a technology for upgrading the biogas produced in anaerobic digesters, converting $\mathrm{CO}_{2}$ into $\mathrm{CH}_{4}$ through the electromethanogenic process. Two different inocula were compared: i) a mixture of biomass from the anode of a MEC and anaerobic granular sludge (BC1); ii) biomass enriched in a methanol-fed upflow anaerobic sludge blanket reactor (UASB) (BC2). Quantitative and qualitative microbial community assessment of the enrichment process on the biocathodes was performed by means of high throughput sequencing of $16 \mathrm{~S} r D N A$ and $16 S \mathrm{rRNA}$ based massive libraries, as well as RT-qPCR of $16 S r R N A$ and $m c r A$ genes. Although BC2 had a faster increase in current density than $\mathrm{BC}$, there were no significant differences neither in the average $\mathrm{CH}_{4}$ production $\left(0.23 \pm 0.01\right.$ and $0.22 \pm 0.05 \mathrm{~L} \mathrm{~m}^{-3} \mathrm{~d}^{-1}$ for $\mathrm{BC} 1$ and $\mathrm{BC} 2$, respectively), nor in the
\end{abstract}


cathodic methane recovery efficiency ( $65 \pm 8$ and $79 \pm 17 \%$, respectively). Independently from the origin of the inoculum, total and active archaeal microbial community in both biocathodes was dominated by hydrogenotrophic methanogenic archaea, especially belonging to Methanobacteriaceae family (mainly Methanobrevibacter genus) (84-98\% of both $16 S$ rDNA and $16 S r R N A$ relative abundance).

KEYWORDS: Electromethanogenesis, biocathode, hydrogenotrophic methanogen, biogas upgrading, gene expression, RNA/cDNA.

\section{INTRODUCTION}

Biogas is a renewable energy carrier gas consisting mainly of methane $\left(\mathrm{CH}_{4}, 40-75 \%\right)$ and carbon dioxide $\left(\mathrm{CO}_{2}, 15-60 \%\right)^{1}$ that is obtained from the anaerobic digestion of bio-degradable materials such as manure, energy crops, household and industry wastes. So far, heating and electricity generation are the main applications of biogas, which are spreading its use as an alternative to fossil fuels. Moreover, it has more efficient uses, such as the injection in the existent natural gas grid or the utilization as transport fuel. For the latter purposes raw biogas needs some treatments prior to its use intended to remove undesired compounds (cleaning) and adjust the calorific value separating $\mathrm{CH}_{4}$ from $\mathrm{CO}_{2}$ (upgrading), obtaining biomethane. Conventional techniques for biogas upgrading, that are focused on $\mathrm{CO}_{2}$ removal without changing $\mathrm{CH}_{4}$ mass, include pressure swing adsorption, membrane separation or chemical $\mathrm{CO}_{2}$ absorption, obtaining a final product with $95-97 \% \mathrm{CH}_{4}$ and $1-3 \% \mathrm{CO}_{2} .{ }^{1}$ An alternative to these enrichment techniques that has recently emerged is the use of microbial electrolysis cells (MEC), in which external energy is supplied to promote a thermodynamic no spontaneous reaction -such as the bioelectrochemical $\mathrm{CO}_{2}$ conversion into methane in a process known as 
electromethanogenesis. ${ }^{2-4}$ This way, the methane yield from anaerobic digestion could be increased. 5,6 The key players of the electromethanogenesis process are hydrogenotrophic methanogenic archaea that develop in the cathode compartment of the MEC (biocathode). Previous studies have demonstrated that methane obtaining from $\mathrm{CO}_{2}$ can be achieved through two different mechanisms of extracellular electron transfer, i) indirectly, through the intermediate abiotic electrochemical and/or microbially catalyzed production of hydrogen in the cathodic compartment (Equation 1 and 2); or ii) directly, by taking the electrons from the cathode and using them to reduce $\mathrm{CO}_{2}$ to methane (Equation 3). ${ }^{2-4}$

$$
\begin{aligned}
& 2 \mathrm{H}^{+}+2 \mathrm{e}^{-} \rightarrow \mathrm{H}_{2} \\
& 4 \mathrm{H}_{2}+\mathrm{CO}_{2} \rightarrow \mathrm{CH}_{4}+\mathrm{H}_{2} \mathrm{O} \\
& \mathrm{CO}_{2}+8 \mathrm{H}^{+}+8 \mathrm{e}^{-} \rightarrow \mathrm{CH}_{4}+2 \mathrm{H}_{2} \mathrm{O}
\end{aligned}
$$

The cathode potential required to enhance the electromethanogenic process due to potential losses is usually in the range from -0.4 to $-1.4 \mathrm{~V}$ (vs. the standard hydrogen electrode, SHE). ${ }^{7}$ At more negative potentials also acetate may be produced simultaneously with $\mathrm{CH}_{4}$ and $\mathrm{H}_{2}$ in a microbial biocathode based on mixed cultures. ${ }^{8}$ However, acetate has been coproduced with methane at a fixed cathode potential as low as $-590 \mathrm{mV}$ (vs, SHE) in another study. ${ }^{9}$

Obtaining an enriched biomass in hydrogenotrophic methanogenic archaea in order to be used as inoculum could accelerate the start up of the methane producing MECs and improve methane production rates, being $\mathrm{CO}_{2} / \mathrm{H}_{2}$ gassing ${ }^{10,11}$ or cultivation in an electrochemical bioreactor ${ }^{8,12}$ the most common enrichment methods. A recently proposed alternative enrichment method was the utilization of a methanol-fed upflow anaerobic sludge blanket reactor (UASB), providing that hydrogenotrophic methanogenesis is one of the possible routes for methanol degradation, besides the predominant methylotrophic route. ${ }^{13}$ The effectiveness of this latter method to increase the 
performance of an electromethanogenic biocathode needs to be further evaluated. Furthermore, a deep study of the biomass harbored by methanogenic biocathodes is needed, applying new techniques such as simultaneous DNA and RNA extraction, quantification and high throughput sequencing, in order to disclose which microorganisms are really active among the ones that might be present in the biofilm. ${ }^{13}$ Previous works have focused only in describing existing microorganisms, without deciphering the active ones. ${ }^{14-16}$

The main aim of this study was to assess the performance and biomass enrichment of the biocathode of a lab-scale MEC to convert $\mathrm{CO}_{2}$ into $\mathrm{CH}_{4}$ as a technology for upgrading the biogas produced in anaerobic digesters, comparing two different inocula: i) a mixture of biomass from the anode of a MEC and anaerobic granular sludge; ii) biomass enriched in a methanol-fed upflow anaerobic sludge blanket reactor (UASB). The microbial enrichment on the biocathodes was assessed in terms of composition and activity using quantitative real-time polymerase chain reaction (qPCR) and high throughput sequencing of 16S rDNA and 16S rRNA massive libraries.

\section{MATERIALS AND METHODS}

Experimental set-up. A pair of identical two-chambered cells ( $0.5 \mathrm{~L}$ each compartment), constructed using methacrylate, were operated (Figure 1). Both compartments were separated by a cation exchange membrane (CEM) (dimensions: 14 x 12 cm; Ultrex CMI-7000, Membranes International Inc., Ringwood, NJ, USA). Each chamber was filled with granular graphite with diameter ranging from 1 to $5 \mathrm{~mm}$ (Typ 00514, enViro-cell Umwelttechnik GmbH, Oberursel, Germany) to act as electrodes (anode and cathode), remaining $265 \mathrm{~mL}$ of net volume in each compartment. Prior to being used, in order to remove metals and organic residues, granular graphite was sequentially submerged in $\mathrm{HCl}(37 \%)$ and $\mathrm{NaOH}(1 \mathrm{M})$ each for 24 hours, and then rinsed in deionized water and dried at $100{ }^{\circ} \mathrm{C} .{ }^{17} \mathrm{An}$ A304 stainless steel mesh was used as electron collector in each compartment (dimensions: $14 \times 12 \mathrm{~cm}$; mesh width: $6 \times 6 \mathrm{~mm}$; wire thickness: $1 \mathrm{~mm}$; Feval Filtros, S.L., Barcelona, Spain). An Ag/AgCl reference electrode (Bioanalytical 
Systems, Inc., USA, +197 mV vs. standard hydrogen electrode (SHE)) was inserted in the cathode (working electrode) compartment, being the anode the counter electrode. A potentiostat (VSP, Bio-Logic, Grenoble, France) was used for data monitoring and poising the cathode potential in a three electrode mode. All potential values in this paper are referred to SHE. Anode and cathode potentials, and current were recorded every $5 \mathrm{~min}$ using a personal computer with EC-Lab software (Bio-Logic, Grenoble, France). The synthetic feeding solutions of the anode and cathode compartments, differing in the carbon source, contained (per liter of deionized water): $\mathrm{NH}_{4} \mathrm{Cl}, 0.87 \mathrm{~g} ; \mathrm{CaCl}_{2}, 14.7 \mathrm{mg} ; \mathrm{KH}_{2} \mathrm{PO}_{4}, 3 \mathrm{~g} ; \mathrm{Na}_{2} \mathrm{HPO}_{4}, 6$ $\mathrm{g} ; \mathrm{MgSO}_{4}, 0.246 \mathrm{~g}$; and $1 \mathrm{~mL} \mathrm{~L}^{-1}$ of a trace elements solution. Additionally $2.9 \mathrm{~g} \mathrm{~L}^{-1}$ of $\mathrm{CH}_{3} \mathrm{COONa}$ and $5 \mathrm{~g} \mathrm{~L}^{-1}$ of $\mathrm{NaHCO}_{3}$ ( since $\mathrm{CO}_{2}$ is mainly present as $\mathrm{HCO}_{3}{ }^{-}$at $\mathrm{pH}$ 7) were added at the anode and cathode solutions, respectively, as carbon source. The solution of trace mineral contained (per liter of deionized water): $\mathrm{FeCl}_{3} \cdot \mathrm{H}_{2} \mathrm{O}, 1.50 \mathrm{~g} ; \mathrm{H}_{3} \mathrm{BO}_{3}, 0.15 \mathrm{~g} ; \mathrm{CuSO}_{4} \cdot 5 \mathrm{H}_{2} \mathrm{O}, 0.03 \mathrm{~g} ; \mathrm{KI}, 0.18 \mathrm{~g} ; \mathrm{MnCl}_{2} \cdot 4 \mathrm{H}_{2} \mathrm{O}, 0.12 \mathrm{~g}$; $\mathrm{Na}_{2} \mathrm{MoO}_{4} \cdot 2 \mathrm{H}_{2} \mathrm{O}, 0.06 \mathrm{~g} ; \mathrm{ZnSO}_{4} \cdot 7 \mathrm{H}_{2} \mathrm{O}, 0.12 \mathrm{~g} ; \mathrm{CoCl}_{2} \cdot 6 \mathrm{H}_{2} \mathrm{O}, 0.15 \mathrm{~g} ; \mathrm{NiCl}_{2} \cdot 6 \mathrm{H}_{2} \mathrm{O}, 0.023 \mathrm{~g}$; EDTA, $10 \mathrm{~g}$.

Reactor operation. The MECs were operated in continuous for 95 days poising the cathode potential at $-800 \mathrm{mV}$ vs SHE. One of the MECs (BC1) was inoculated, both the anode and the cathode compartment, with $30 \mathrm{~mL}$ of a mixture 3.6:1 of the biomass of the anode of a mother MEC treating digested pig slurry ${ }^{18}$ and granular biomass from a full-scale AD, with a volatile suspended solids (VSS) content of $16 \mathrm{~g} \mathrm{~L}^{-1}$. The same mixture was used to inoculate the anode of the second MEC (BC2). In this case, the cathode was inoculated with $30 \mathrm{~mL}$ of a resuspension (VSS content of $33 \mathrm{~g} \mathrm{~L}^{-1}$ ) of the anaerobic granular sludge of an UASB that had been operated with methanol in order to enrich the biomass with methanogenic archaea. ${ }^{13}$ The resuspension was done by vortex mixing during 10 minutes in a $50 \mathrm{~mL}$ tube containing $30 \mathrm{~g}$ of granular sludge and $25 \mathrm{~mL}$ of Ringer $1 / 4$ sterilized solution. The influent solutions of both the anode and the cathode compartments were fed in continuous with a pump at $40 \mathrm{~mL} \mathrm{~h}^{-1}$ and recirculated with an external pump. The hydraulic retention time (HRT) of each compartment was of $6.8 \mathrm{~h}$ (with 
respect to the net volume of each compartment), and the organic loading rate (OLR) of the anode compartment was established at $7.83 \mathrm{~kg}_{\mathrm{COD}} \mathrm{m}^{-3} \mathrm{day}^{-1}$. The MECs were operated at room temperature during the entire assay $\left(23 \pm 2^{\circ} \mathrm{C}\right)$.

Analytical methods and calculations. Samples of the effluent of each compartment were analyzed for pH using a CRISON 2000 pH electrode, besides chemical oxygen demand (COD) in the anode compartment samples, according to Standard Methods 5220. ${ }^{19}$ Methane was measured (through the determination of dissolved methane) in the cathode samples according to Henry's Law and the following method. ${ }^{20}$ Around $2 \mathrm{~mL}$ catholyte samples were collected with a $5 \mathrm{~mL}$ syringe and injected with a needle in a $4 \mathrm{~mL}$ vacutainer. The vacutainers were shaken vigorously for $30 \mathrm{~s}$ and then allowed to stand for $1 \mathrm{~h}$. Headspace gas was analyzed for $\mathrm{CH}_{4}$ using a gas chromatograph (CP-3800, Varian, USA). Dissolved $\mathrm{CH}_{4}$ was computed using the equation:

$$
X_{L}=\frac{C_{\mathrm{CH}_{4}} \cdot M V_{\mathrm{CH}_{4}} \cdot M W_{\mathrm{CH}_{4}} \cdot\left(V_{T}-V_{L}+\alpha V_{L}\right) \cdot 1000}{V_{L}}
$$

where $X_{L}$ is the concentration of $\mathrm{CH}_{4}\left(\mathrm{mg} \mathrm{L}^{-1}\right)$ in the solution, $C_{C H 4}$ is the concentration of $\mathrm{CH}_{4}$ (\%) in the headspace $1 \mathrm{~h}$ after shaking, $M V_{C H 4}$ is the molar volume of $\mathrm{CH}_{4}$ at $25^{\circ} \mathrm{C}\left(0.041 \mathrm{~mol} \mathrm{~L}^{-}\right.$ $\left.{ }^{1}\right), M W_{C H 4}$ is the molecular weight of $\mathrm{CH}_{4}\left(16 \mathrm{~g} \mathrm{~mol}^{-1}\right), V_{T}$ is the volume $(\mathrm{mL})$ of the vacutainer, $V_{L}$ is the volume $(\mathrm{mL})$ of the solution, and $\alpha$ is the water:air partition coefficient at $25^{\circ} \mathrm{C}(0.03)$. Methane production was normalized to the net volume of the cathode compartment $(0.265 \mathrm{~L})$.

COD removal efficiency in the MECs was calculated based on the difference between anode influent and effluent concentrations divided by the influent concentration.

Electrochemical measurements and calculations. The current density $\left(\mathrm{A} \mathrm{m}^{-3}\right)$ of the MECs was calculated as the quotient between the current recorded by the potentiostat (A) and the net volume of the anode $\left(\mathrm{m}^{3}\right)$. 
The Coulombic efficiency (CE), or the fraction of electrons obtained from the consumption of COD at the anode compartment that are available for methane production at the cathode (Equation 5), the energy efficiency relative to electrical input recovered as methane $\left(\mathrm{EE}_{\mathrm{e}}\right.$, Equation 6), the energy efficiency relative to the energy content of the substrate $\left(\mathrm{EE}_{\mathrm{s}}\right.$, Equation 7) and the energy efficiency with respect to the energy input and the energy in the substrate $\left(\mathrm{EE}_{\mathrm{e}+\mathrm{s}}\right.$, Equation 8) were calculated as:

$$
\begin{aligned}
& \mathrm{CE}=\frac{\mathrm{M} \int_{0}^{\mathrm{t}} \mathrm{Idt}}{\mathrm{F} \mathrm{b} \mathrm{q} \triangle \mathrm{COD}} \\
& E_{\mathrm{e}}=\frac{\mathbf{n}_{\mathrm{CH}_{4}} \Delta \mathrm{G}_{\mathrm{CH}_{4}}}{\int_{0}^{\mathrm{t}} \mathrm{I} \mathrm{E}_{\mathrm{ap}} \mathrm{dt}} \\
& \mathbf{E E}_{s}=\frac{\mathbf{n}_{\mathrm{CH}_{4}} \Delta \mathrm{G}_{\mathrm{CH}_{4}}}{\mathbf{n}_{\mathrm{S}} \Delta \mathrm{G}_{\mathrm{S}}} \\
& E_{\mathrm{e}+\mathrm{s}}=\frac{\mathrm{n}_{\mathrm{CH}_{4}} \Delta \mathrm{G}_{\mathrm{CH}_{4}}}{\int_{0}^{\mathrm{t}} \mathrm{IE} \mathrm{E}_{\mathrm{ap}} \mathrm{dt}+\mathrm{n}_{\mathrm{s}} \Delta \mathrm{G}_{\mathrm{S}}}
\end{aligned}
$$

where $M$ is the molecular weight of the final electron acceptor, $I$ is the current (A), $F$ is Faraday's constant $\left(96485 \mathrm{C} \mathrm{mol}^{-1}\right), b$ is the number of electrons transferred per mole of $\mathrm{O}_{2}, q$ is the volumetric influent flow rate $\left(\mathrm{L} \mathrm{d}^{-1}\right), \triangle C O D$ is the difference in the influent and effluent $\mathrm{COD}, n_{\mathrm{CH} 4}$ are the moles of produced methane, $\Delta G_{\mathrm{CH} 4}$ is the molar Gibbs free energy of $\mathrm{CH}_{4}$ oxidation by oxygen to carbon dioxide $\left(-817.97 \mathrm{~kJ} \mathrm{~mol}^{-1}\right), E_{a p}$ is the applied voltage calculated as the difference between the cathode and anode potentials $(\mathrm{V}), n_{S}$ are the moles of acetate consumed and $\Delta G_{S}$ is the molar Gibbs free energy of acetate oxidation to carbon dioxide ($844.61 \mathrm{~kJ} \mathrm{~mol}^{-1}$ ). 
Finally, the cathodic methane recovery efficiency $\left(\mathrm{R}_{\mathrm{cat}}\right)$, defined as the fraction of electrons reaching the cathode that are recovered as methane, was calculated as:

$$
\mathbf{R}_{\mathrm{cat}}=\frac{8 \mathrm{~F} \mathbf{n}_{\mathrm{CH}_{4}}}{\int_{0}^{\mathrm{t}} \mathrm{Idt}}
$$

Cyclic voltammetries $(\mathrm{CV})$ in turnover conditions, i.e. in the presence of substrate, were performed using a potentiostat (VSP, Bio-Logic, Grenoble, France) at the start (day 0) and the end (day 95) of the assays in each biocathode, in order to study the electroactive microbial biofilms developed on the cathodes. The same three-electrode configuration used for the MECs operation was maintained for the set up of the CV. The start $\left(E_{i}\right)$ and vertex $\left(E_{f}\right)$ potentials were 800 and $400 \mathrm{mV}$ vs SHE, respectively, and the scan rate was set at $1 \mathrm{mV} \mathrm{s}^{-1}$.

Microbial community analysis. The bacterial communities in both inoculums used for the cathodes of $\mathrm{BC} 1$ and $\mathrm{BC} 2$ and the biofilm harbored in the same electrodes at the end of the assay were analyzed by culture-independent molecular techniques such as (RT) quantitative PCR (RTqPCR) and high throughput sequencing (MiSeq, Illumina). To keep the nucleic acids stable, especially RNA, samples were stored at $-80^{\circ} \mathrm{C}$.

Nucleic acid extraction and cDNA synthesis. Total DNA and RNA were extracted simultaneously in triplicate from known weights of each sample, which consisted on granular sludge for the inoculums and granular graphite collected from the cathode compartments for the biocathode biofilm. The PowerMicrobiome ${ }^{\mathrm{TM}}$ RNA Isolation Kit (MoBio Laboratories Inc., Carlsbad, CA, USA) was used according to manufacturer's instructions, and cDNA was obtained from RNA following the protocol described elsewhere. ${ }^{13}$ Throughout the paper, cDNA quantification (16S rRNA and mcrA genes) and 16S rRNA (cDNA) sequencing results refer to active microorganisms. 
Quantitative PCR assay (qPCR). Gene copy numbers of eubacterial $16 S r R N A$ gene and $m c r A$ gene (methanogenic archaeal methyl coenzyme-M reductase) were quantified by means of quantitative real-time PCR (qPCR). Each sample was analyzed in triplicate by means of the three independent DNA and RNA extracts. The analysis was carried out by using Brilliant II SYBR Green qPCR Master Mix (Stratagene, La Jolla, CA, USA) in a Real-Time PCR System Mx3000P (Stratagene) operated with the protocol described elsewhere. ${ }^{18}$

The standard curve parameters of the qPCRs were as follows (for $16 S$ rRNA and mcrA, respectively): slope of -3.244 and -3.532 ; correlation coefficient of 0.998 and 0.999 ; efficiency of 103 and $92 \%$; showing that the reactions performed had a high efficiency.

High throughput sequencing and data analysis. The same DNA and RNA extracts from the inocula and the biofilms from the biocathodes used for qPCR analysis were also used for 16Sbased high throughput sequencing purposes (MiSeq), following the specific steps described elsewhere. ${ }^{18}$ Bayesian Classifier database of the Ribosomal Database Group (RDP) was used to taxonomically classify the obtained Operational Taxonomic Units (OTUs). ${ }^{21}$

The data obtained from sequencing datasets for eubacterial and archaeal populations were submitted to the Sequence Read Archive of the National Center for Biotechnology Information (NCBI) under the study accession number SRP072511.

Statistical correspondence analysis of MiSeq data was performed by means of XLSTAT 2014 software (Addinsoft, Paris, France). The diversity of the samples was evaluated with the number of OTUs, the inverted Simpson index, Shannon index and Goods coverage using the Mothur software v.1.34.4 (http://www.mothur.org), ${ }^{22}$ normalizing all the estimators to the lowest number of reads among the different samples.

\section{RESULTS AND DISCUSSION}


Operation performance. The current densities produced by the $\mathrm{BC} 1$ and the $\mathrm{BC} 2$ during the 95 days of operation are shown in Figure S1a and S1b, respectively. The BC2 achieved current densities between 150 and $200 \mathrm{~A} \mathrm{~m}^{-3}$ after 5 days of operation, while the $\mathrm{BC} 1$ showed a more progressive increase (the low current densities between days 8 and 14 are due to a MEC destabilization after the performance of a cyclic voltammetry). However, the BC1 maintained a current density between 100 and $150 \mathrm{~A} \mathrm{~m}^{-3}$ from day 50 on, while the $\mathrm{BC} 2$ produced a current density around $80 \mathrm{~A} \mathrm{~m}^{-3}$. Nevertheless, the average methane production was similar in both MECs, 0.22-0.23 $\mathrm{m}^{3} \mathrm{~m}^{-3} \mathrm{~d}^{-1}$ (Table 1). It is noteworthy that the obtained values are twenty-fold and ten-fold higher, in terms of current density and methane production respectively than those reported previously in a dual-chamber methanogenic MEC using graphite granules as electrodes, with current density generation and methane production rate of $9.3 \mathrm{~A} \mathrm{~m}^{-3}$ and $0.018 \mathrm{~m}^{3} \mathrm{~m}^{-3} \mathrm{~d}^{-1}$, respectively; ${ }^{3}$ they are also higher than those achieved from a spiral-wound-electrode MEC with an applied voltage of $1.2 \mathrm{~V}$, with a current density generation and methane production rate of $109 \mathrm{~A} \mathrm{~m}^{-3}$ and $0.16 \mathrm{~m}^{3} \mathrm{~m}^{-3} \mathrm{~d}^{-1}$, respectively. ${ }^{12}$ Even $0.28 \mathrm{~m}^{3} \mathrm{~m}^{-3} \mathrm{~d}^{-1}$ were achieved in a MEC with a semi-batch fed cathode. ${ }^{23}$

Regarding the cathodic methane recovery efficiency $\left(\mathrm{R}_{\mathrm{cat}}\right)$ and energy efficiencies $\left(\mathrm{EE}_{\mathrm{e}}, \mathrm{EE}_{\mathrm{s}}\right.$ and $\mathrm{EE}_{\mathrm{e}+\mathrm{s}}$ ), the values obtained for $\mathrm{BC} 2$ are higher than those of $\mathrm{BC} 1$, but due to the instability of BC2 performance these values have a higher variability (Table 1). Previous works with a twochambered MEC using graphite granules as electrodes have achieved an energy efficiency related to the electrical energy input $\left(\mathrm{EE}_{\mathrm{e}}\right)$ and of electrical input and substrate $\left(\mathrm{EE}_{\mathrm{e}+\mathrm{s}}\right)$ of $57 \%$ and $30 \%$, respectively, in batch mode, ${ }^{3}$ values very similar to the ones obtained in this study. On the contrary, the $\mathrm{CE}$ achieved $(33 \pm 10$ for $\mathrm{BC} 1$ and $25 \pm 12$ for $\mathrm{BC} 2)$ are lower than previously reported, such as $72-80 \% .{ }^{24}$ Possible sinks of electrons include methanogenesis, oxidation by 
electron acceptors other than the anode, acetate conversion to microbial carbon storage molecules and bacterial growth. ${ }^{25}$ The potential of the anode as electron acceptor determines the bacterial yield through the energy gain per electron transferred. ${ }^{25}$ In this study, anode potentials were on average $0.05 \mathrm{~V}$ and $0.4 \mathrm{~V}$ in $\mathrm{BC} 1$ and $\mathrm{BC} 2$, respectively. The higher the anode potential, the higher the energy gain for bacteria and growth. The high anode potential, particularly of $\mathrm{BC} 2$, was probably promoting a higher loss of electrons on bacterial growth, resulting in a low CE. Finally, the obtained $\mathrm{R}_{\text {cat }}(65 \pm 8$ for $\mathrm{BC} 1$ and $79 \pm 17$ for $\mathrm{BC} 2)$ are below the $96 \%$ previously reported by Cheng et al. ${ }^{2}$ or the $84-86 \%$ obtained by Zeppilli et al., ${ }^{24}$ but much higher than the $23.1 \%$ achieved by Van Eerten-Jansen et al. ${ }^{5}$ or the $24.2 \pm 4.7 \%$ reported by Zhen et al. ${ }^{26}$

Figure S2 shows the cyclic voltammograms obtained in both biocathodes at the start (day 0) and the end (day 95) of their operation. The curves obtained at the start of the operation showed a low response to the different applied potentials, as a result of the recent inoculation. At the end of the assay the curves showed that the biofilm was established in both biocathodes, with a better performance of BC2 at potentials lower than $-330 \mathrm{mV}$ vs. SHE. However, the current densities obtained during the continuous operation of the MECs were lower than those achieved in the cyclic voltammetries, especially in BC2. Catalytic current for both biocathodes had an onset at approximately $-300 \mathrm{mV}$, that could be related to the reduction of $\mathrm{CO}_{2}$ to methane $\left(E^{\prime}=-237\right.$ to $303 \mathrm{mV}$ for $\mathrm{pH} 7-8)$ or acetate $\left(E^{\prime}=-287\right.$ to $-352 \mathrm{mV}$ for $\left.\mathrm{pH} 7-8\right)$, in the case that this product was generated in the cathode compartment. ${ }^{27} \mathrm{~A}$ second onset appeared at a potential near -800 $\mathrm{mV}$, which might be related to the hydrogen evolution reaction $\left(2 \mathrm{H}^{+}+2 \mathrm{e}^{-} \rightarrow \mathrm{H}_{2}\right){ }^{28}$ so it is possible that $\mathrm{H}_{2}$ was formed at the biocathode and immediately consumed by hydrogenotrophic methanogens. 


\section{Evaluation of the electromethanogenic MEC as a biogas upgrading technology. With the} obtained results of methane conversion from $\mathrm{CO}_{2}\left(0.23 \mathrm{~m}^{3} \mathrm{~m}^{-3} \mathrm{~d}^{-1}\right)$, the performance of the electromethanogenic MEC as a biogas upgrading technology was assessed. Up to $0.58 \mathrm{~m}^{3} \mathrm{~m}^{-3} \mathrm{~d}^{-1}$ of biogas (composition of $60 \% \mathrm{CH}_{4}$ and $40 \% \mathrm{CO}_{2}$ ) could be treated in this biocathode to obtain near $100 \% \mathrm{CH}_{4}$. This way, $1 \mathrm{~m}^{3} \mathrm{~m}^{-3} \mathrm{~d}^{-1}$ of biogas could be treated to obtain a composition of $83 \% \mathrm{CH}_{4}$ and $17 \% \mathrm{CO}_{2}$. When compared to the existing biogas upgrading technologies, that achieve a methane purity of $95-97 \%{ }^{1}$ it has to be taken into account that these technologies remove $\mathrm{CO}_{2}$, without changing $\mathrm{CH}_{4}$ mass, so the final volume of gas obtained is reduced. That is, for each $\mathrm{m}^{3}$ of biogas treated on traditional biogas upgrading technologies, about $0.6 \mathrm{~m}^{3}$ of $\mathrm{CH}_{4}$ would be recovered, while in the biocathode the obtained volume would be of $0.9 \mathrm{~m}^{3}$. Since higher cathodic methane recovery efficiencies have been achieved in previous studies, ${ }^{2}$ and the designs and materials for biocathodes are constantly improving, ${ }^{12}$ a better performance for this new biogas upgrading technology can be expected in the future, so further research is needed focused on its scaling up.

\section{Microbial community assessment.}

Quantitative evolution of cathode biomass. qPCR results of the 4 samples, regarding DNA (present microorganisms) for both $16 \mathrm{~S}$ rRNA (eubacteria) and mcrA (methanogenic archaea) showed higher gene copy numbers in the final BC2 biofilm than in $\mathrm{BC} 1$, although of the same order of magnitude (Figure 2). However, when looking at cDNA (active microorganisms), methanogenic archaea in $\mathrm{BC} 1$ biofilm revealed themselves more active than in $\mathrm{BC} 2$, with more than one order of magnitude increase $\left(2.95 \cdot 10^{5}\right.$ and $9.86 \cdot 10^{3} \mathrm{mcr} A$ transcript copy numbers $\mathrm{g}^{-1}$, respectively); while eubacteria $16 \mathrm{~S}$ rRNA gene copy numbers in the BC2 biofilm were 3.2 times higher than in $\mathrm{BC} 1$. In spite of the quantitative differences of methanogenic archaea between 
both biocathodes, no significant differences were observed related to methane production, so other mechanisms may be affecting the performance of the biomass. It could be possible that the highest number of active eubacteria in the BC2 increased the synergies with archaea, which could help to overcome their lower number in comparison with $\mathrm{BC} 1$, as will be discussed in the following section.

Sequencing results for eubacteria and archaea. Table S1 shows the number of reads obtained for the inoculums and the final biofilm of the biocathodes for eubacteria (3538 OTUS) and archaea (725 OTUS). Figure 3a shows the relative abundance of eubacterial phyla for the four samples, regarding DNA (present microorganisms) and cDNA (active microorganisms) forms. Both inoculums had a different composition, with a higher relative predominance of Proteobacteria (57\%) and Bacteroidetes (61\%) in the inoculums of BC1 and BC2, respectively, while at the end of the assays the biofilms where enriched the opposite (45\% for Bacteroidetes and $58 \%$ for Proteobacteria in $\mathrm{BC} 1$ and $\mathrm{BC} 2$, respectively). The most active phyla in $\mathrm{BC} 1$ biofilm were, according to cDNA results, Bacteroidetes (37\%), Firmicutes (33\%) and Proteobacteria (27\%), while Proteobacteria phylum (73\%) was highly active in $\mathrm{BC} 2$ biofilm. A previous study also found that Proteobacteria was the most predominant phylum in an electromethanogenic biocathode (54\% of the clones in the library). ${ }^{29}$ At family level (Figure 3b), Cyclobacteriaceae was the predominant one in the BC1 biofilm (30\%), in spite of being Pseudomonadaceae the most abundant family in the inoculum (46\%). In the BC2 biofilm four families accounted for the same relative abundance (11\%): Desulfovibrionaceae, Cyclobacteriaceae, Pseudomonadaceae and Rhodocyclaceae, while they had a low relative abundance in the inoculum (below $3 \%$ for Desulfovibrionaceae and below $0.25 \%$ for the three other families). When looking at the cDNA form, and thereby active microorganisms, Cyclobacteriaceae family maintained its higher 
relative abundance (25\%), accompanied by Eubacteriaceae $(13 \%)$ in the BC1 biofilm. However, the most active families in the BC2 biofilm where Desulfobacteraceae and Desulfovibrionaceae (22 and 20\%, respectively), although being practically inactive in the inoculum. Therefore, these results suggest on the one hand that the active groups of microorganisms differ from the most abundant ones; and on the second hand, the enrichment of eubacteria on the electromethanogenic biocathodes under the same operational conditions may be different, which is consistent with a

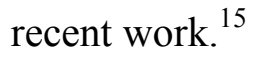

Pseudomonas was one of the genera identified in the biocathodes with a higher relative abundance ( 2 and $7 \%$ of active microorganisms in $\mathrm{BC} 1$ and $\mathrm{BC} 2$, respectively). Certain species, such as Pseudomonas aeruginosa, have been described in microbial fuel cell (MFC) anodes, and are able to potentially produce several shuttling compounds that facilitate electrochemical activity. ${ }^{30}$ The clear enrichment of OTUs belonging to this genus after inoculation suggest a role in the biocathode processes. A similar enrichment was observed for Geobacter, a well known exoelectrogenic eubacteria, which represented 3 and $4 \%$ of active microorganisms in $\mathrm{BC} 1$ and $\mathrm{BC} 2$, respectively. Geobacter is able to catalyze bioelectrochemical hydrogen production at the cathode, ${ }^{31,} 32$ and may be involved in the production of methane through the microbiallycatalyzed production of $\mathrm{H}_{2}$ (equation 1 and 2). Other remarkable genus because of its relative abundance was Desulfovibrio ( 7 and $20 \%$ of active microorganisms in BC1 and BC2, respectively), belonging to Desulfovibrionaceae family. Sulfate reducing species such as Desulfovibrio have been reported involved in sulfide-mediated electron transfer in anodes. ${ }^{33}$ Since the latter family is more abundant in $\mathrm{BC} 2$, it could be the reason for its similar methane production to $\mathrm{BC} 1$ in spite of the lower copy number of transcripts of $m c r \mathrm{~A}$ gene obtained by RT-qPCR. Furthermore, Desulfovibrio may also be involved in the production of methane 
through the microbially-catalyzed production of $\mathrm{H}_{2}$, as described above for Geobacter. Finally, Acetobacterium, belonging to Eubacteriaceae family, which has been identified previously in methanogenic cathodes, $4,14,15$ was particularly enriched in $\mathrm{BC} 1$ (11 and $0.1 \%$ of active microorganisms in $\mathrm{BC} 1$ and $\mathrm{BC} 2$, respectively). Acetobacterium is a typical cathodic acetogen, ${ }^{9}$ and its presence could indicate that electrons were not exclusively directed to methanogenesis, explaining the cathodic methane recovery below $100 \%$ obtained in both biocathodes. The cathodic methane recovery was slightly lower in BC1 than in BC2 (65 $\mathrm{B}$ and $79 \pm 17$, respectively), which also presented the highest relative abundance for Acetobacterium. This hypothesis is reinforced by the fact that small amounts of acetate were detected in the cathode effluent $\left(<33 \mathrm{mg} \mathrm{L}^{-1}\right)$. Therefore, the role of the described eubacteria genera may reinforce and countervail lower number of methanogenic population in $\mathrm{BC} 2$ and explain the similar methane production in both biocathodes.

Regarding archaea population, Figure 4 shows a clear enrichment in Methanobacteriaceae family in both biocathodes, especially in $\mathrm{BC} 2$ (90\% of relative abundance), belonging mainly to Methanobrevibacter genus. Apart from its high relative abundance, it also revealed as the most active family ( 87 and $98 \%$ in $\mathrm{BC} 1$ and $\mathrm{BC} 2$, respectively). Previous work also determined that Methanobacteriaceae was the predominant family on methanogenic biocathodes, although identifying Methanobacterium as the predominant species, ${ }^{4,6,26}$ such as $86.7 \%$ using fluorescent in situ hybridization (FISH) in a two-chamber electrochemical reactor containing an abiotic anode and a biocathode for methane production, ${ }^{2}$ or $>93 \%$ of the total sequenced active archaeal reads in a MEC with concomitant production of acetate, methane and hydrogen. ${ }^{9}$ Methanobacterium dominated also on the biocathodes, with lesser members of Methanobrevibacter, in MECs inoculated with either anaerobic bog sediment where 
hydrogenotrophic methanogens were detected or anaerobic digestion sludge dominated by the acetoclastic Methanosaeta. ${ }^{14}$ Instead, Methanobrevibacter was found to dominate the biofilms developed on platinum cathodes (81-100\%), while Methanobacterium abounded on the other cathode materials assayed (median of $97 \%$ in abundance of all archaea), when the inoculum used contained primarily the genus Methanosaeta $(95 \%) .{ }^{15}$ Methanobacterium, Methanobrevibacter and Methanocorpusculum dominated the biocathode of another MEC at an applied voltage of 0.7 $\mathrm{V}^{10}$ and Methanobrevibacter and Methanosarcina were observed in a MEC with a cathode of graphite granules. ${ }^{24}$ Therefore, regardless of the initial composition of the inoculums used, in this study, a convergent enrichment towards hydrogenotrophic methanogenic families was clear, especially in the case of the inoculum of $\mathrm{BC} 2$, which was initially enriched in methylotrophic methanogenic archaea (Methanomassiliicoccaceae, ${ }^{34}$ 24\%, and Methanosarcinaceae, 50\%, genus Methanomethylovorans and Methanolobus ${ }^{35,36}$ ). Methanobrevibacter genus, along with Methanobacterium found in other studies, seem to be especially adapted for growth in electromethanogenic MECs, as stated in a previous work, ${ }^{15}$ differentiating from other hydrogenotrophic methanogens under poised potentials. Recently, it has been stated that the predominance of these genera may be due to the fact that they do not require complex carbon sources and growth factors such as vitamins and amino acids, while other hydrogenotrophic species are known to require acetate as a carbon source or peptone as a growth factor. ${ }^{37}$

Biodiversity analysis. Table S1 shows the results for the biodiversity analysis performed on inoculums and final biocathode biofilm samples. The Inverted Simpson and Shannon indexes for eubacteria and archaea population showed that in general biodiversity decreased when looking at the really active population in biofilms with respect to the present one. Eubacteria population in 
the final biofilm of $\mathrm{BC} 2$ was the richest, both in presence and in activity according to the Inverted Simpson index (16.36 and 9.90, respectively), while archaea population was richer in the final biofilm of $\mathrm{BC} 1$ (2.46 and 2.30 for DNA and cDNA, respectively). These results agree with the high relative abundance of Methanobacteriaceae in BC2 found in the MiSeq 16S-based sequencing analysis, which reduces its biodiversity. On the other hand, the final biocathode biofilms showed a lower biodiversity compared to the inoculums regarding archaea community, as a result of their high enrichment in Methanobrevibacter. Eubacteria increased its biodiversity in $\mathrm{BC} 2$ compared to the inoculum, which disagree with the results of a previous work that found the opposite behavior. ${ }^{15}$

Correspondence analysis. Correspondence analysis results for eubacteria and archaea community are shown in Figure S3a and S3b. The evolution from the inoculums to the final biocathode biofilms was similar for both populations. Results show a clear differentiation between $\mathrm{BC} 1$ and $\mathrm{BC} 2$ inoculums but, in spite of their diverse initial composition, their populations evolved on the biocathodes towards consortiums that were clearly clustered together at the end of the assay, as a clear example of convergent microbial enrichment. Furthermore, DNA and cDNA for each sample were prochain, indicating that the active populations were similar to the existing ones, in spite of the differences detected by the MiSeq sequencing. These results corroborate that a very specific archaea population was obtained under the strict operation conditions of both biocathodes, and that the different inocula used had little influence on the final composition and activity, as was also suggested by the results obtained regarding methane production and operation performance. 
Results showed that the origin of the biomass tested in this study had little influence on the performance of the biocathode, since methane productions and energy efficiencies were similar in two cells with different inoculum composition. Both inoculums converged at the end of the MECs operation in a similar composition, especially for the archaeal communities, highly dominated by hydrogenotrophic methanogenic archaea. Methanobrevibacter revealed itself as the most active family in the cathode biofilm, according to the RNA-based high throughput sequencing. Further research is needed to make electromethanogenic biocathode MEC (based on $\mathrm{CO}_{2}$ conversion into $\mathrm{CH}_{4}$ ) a promising technology for biogas upgrading, able to compete in the future with the existing technology (based on $\mathrm{CO}_{2}$ removal).

\section{ASSOCIATED CONTENT}

Table S1: diversity indexes

Figures S1-S3: S1 (current density profiles); S2 (cyclic voltammograms); S3 (correspondence analysis).

\section{AUTHOR INFORMATION}

\section{Corresponding Author}

*E-mail: august.bonmati@irta.cat (A. Bonmatí)

\section{Notes}

The authors declare no competing financial interest. 


\section{ACKNOWLEDGMENTS}

The authors would like to acknowledge the valuable contribution to this work of Miriam Guivernau (GIRO Joint Research Unit IRTA-UPC), for the implementation of the protocols of RT-qPCR and simultaneous DNA and RNA extraction with cDNA synthesis. This research was funded by the Spanish Ministry of Economy and Competitiveness (INIA projects RTA201200096-00-00 and RTA2015-00079-C02-01) and the CERCA Programme (Generalitat de Catalunya). The first author was supported by a $\mathrm{PhD}$ grant from the Secretariat for Universities and Research of the Ministry of Economy and Knowledge of the Catalan Government (predoctoral grant 2013FI_B 00014).

\section{REFERENCES}

1. Ryckebosch, E.; Drouillon, M.; Vervaeren, H., Techniques for transformation of biogas to biomethane. Biomass and Bioenergy 2011, $35 \quad$ (5), 1633-1645. DOI:10.1016/j.biombioe.2011.02.033.

2. Cheng, S.; Xing, D.; Call, D. F.; Logan, B. E., Direct biological conversion of electrical current into methane by electromethanogenesis. Environmental Science \& Technology 2009, 43 (10), 3953-3958. DOI: 10.1021/es803531g.

3. Villano, M.; Monaco, G.; Aulenta, F.; Majone, M., Electrochemically assisted methane production in a biofilm reactor. Journal of Power Sources 2011, 196 (22), 9467-9472. DOI: 10.1016/j.jpowsour.2011.07.016. 
4. Van Eerten-Jansen, M. C. A. A.; Veldhoen, A. B.; Plugge, C. M.; Stams, A. J. M.; Buisman, C. J. N.; Ter Heijne, A., Microbial community analysis of a methane-producing biocathode in a bioelectrochemical system. Archaea 2013, 2013, 12. DOI: 10.1155/2013/481784.

5. Van Eerten-Jansen, M. C. A. A.; Heijne, A. T.; Buisman, C. J. N.; Hamelers, H. V. M., Microbial electrolysis cells for production of methane from $\mathrm{CO}_{2}$ : long-term performance and perspectives. International Journal of Energy Research 2011, 36 (6), 809-819. DOI: 10.1002/er.1954.

6. Xu, H.; Wang, K.; Holmes, D. E., Bioelectrochemical removal of carbon dioxide $\left(\mathrm{CO}_{2}\right)$ : An innovative method for biogas upgrading. Bioresource Technology 2014, 173, 392-398. DOI: 10.1016/j.biortech.2014.09.127.

7. Geppert, F.; Liu, D.; van Eerten-Jansen, M.; Weidner, E.; Buisman, C.; ter Heijne, A., Bioelectrochemical power-to-gas: State of the art and future perspectives. Trends in Biotechnology 2016, 34 (11), 879-894. DOI: 10.1016/j.tibtech.2016.08.010.

8. Jiang, Y.; Su, M.; Zhang, Y.; Zhan, G.; Tao, Y.; Li, D., Bioelectrochemical systems for simultaneously production of methane and acetate from carbon dioxide at relatively high rate. International Journal of Hydrogen Energy 2013, 38 (8), 3497-3502. DOI: 10.1016/j.ijhydene.2012.12.107

9. Marshall, C. W.; Ross, D. E.; Fichot, E. B.; Norman, R. S.; May, H. D., Electrosynthesis of commodity chemicals by an autotrophic microbial community. Applied and Environmental Microbiology 2012, 78 (23), 8412-8420. DOI: 10.1128/AEM.02401-12. 
10. Jiang, Y.; Su, M.; Li, D., Removal of sulfide and production of methane from carbon dioxide in microbial fuel cells-microbial electrolysis cell (MFCs-MEC) coupled system. Applied Biochemistry and Biotechnology 2014, 172 (5), 2720-2731. DOI: 10.1007/s12010-0130718-9.

11. Villano, M.; Aulenta, F.; Ciucci, C.; Ferri, T.; Giuliano, A.; Majone, M., Bioelectrochemical reduction of $\mathrm{CO}_{2}$ to $\mathrm{CH}_{4}$ via direct and indirect extracellular electron transfer by a hydrogenophilic methanogenic culture. Bioresource Technology 2010, 101 (9), 3085-3090. DOI: 10.1016/j.biortech.2009.12.077.

12. Hou, Y.; Zhang, R.; Luo, H.; Liu, G.; Kim, Y.; Yu, S.; Zeng, J., Microbial electrolysis cell with spiral wound electrode for wastewater treatment and methane production. Process Biochemistry 2015, 50 (7), 1103-1109. DOI: 10.1016/j.procbio.2015.04.001.

13. Cerrillo, M.; Morey, L.; Viñas, M.; Bonmatí, A., Assessment of methanogenic active archaea in a methanol-fed upflow anaerobic sludge blanket reactor. Applied Microbiology and Biotechnology 2016, 100, 10137-10146. DOI: 10.1007/s00253-016-7862-4.

14. Siegert, M.; Li, X.-f.; Yates, M. D.; Logan, B. E., The presence of hydrogenotrophic methanogens in the inoculum improves methane gas production in microbial electrolysis cells. Frontiers in Microbiology 2015, 5 (778). DOI: 10.3389/fmicb.2014.00778.

15. Siegert, M.; Yates, M. D.; Spormann, A. M.; Logan, B. E., Methanobacterium dominates biocathodic archaeal communities in methanogenic microbial electrolysis cells. ACS Sustainable Chemistry \& Engineering 2015, 3 (7), 1668-1676. DOI: 10.1021/acssuschemeng.5b00367. 
16. Cai, W.; Liu, W.; Yang, C.; Wang, L.; Liang, B.; Thangavel, S.; Guo, Z.; Wang, A., Biocathodic methanogenic community in an integrated anaerobic digestion and microbial electrolysis system for enhancement of methane production from waste sludge. ACS Sustainable Chemistry \& Engineering 2016, 4 (9), 4913-4921. DOI: 10.1021/acssuschemeng.6b01221.

17. Sotres, A.; Cerrillo, M.; Viñas, M.; Bonmatí, A., Nitrogen removal in a two-chambered microbial fuel cell: establishment of a nitrifying-denitrifying microbial community on an intermittent aerated cathode. Chemical Engineering Journal 2016, 284, 905-916. DOI: 10.1016/j.cej.2015.08.100.

18. Cerrillo, M.; Viñas, M.; Bonmatí, A., Overcoming organic and nitrogen overload in thermophilic anaerobic digestion of pig slurry by coupling a microbial electrolysis cell. Bioresource Technology 2016, 216, 362-372. DOI: 10.1016/j.biortech.2016.05.085.

19. APHA, Standard methods for the examination of water and wastewater. 20th ed.; American Public Health Association, American Water Works Association, and Water Pollution Control Federation: Washington, D.C., 1999.

20. Alberto, M. C. R.; Arah, J. R. M.; Neue, H. U.; Wassmann, R.; Lantin, R. S.; Aduna, J. B.; Bronson, K. F., A sampling technique for the determination of dissolved methane in soil solution. Chemosphere - Global Change Science 2000, 2 (1), 57-63. DOI: 10.1016/S14659972(99)00044-6.

21. Wang, Q.; Garrity, G. M.; Tiedje, J. M.; Cole, J. R., Naïve bayesian classifier for rapid assignment of rRNA sequences into the new bacterial taxonomy. Applied and Environmental Microbiology 2007, 73 (16), 5261-5267. DOI: 10.1128/AEM.00062-07. 
22. Schloss, P. D.; Westcott, S. L.; Ryabin, T.; Hall, J. R.; Hartmann, M.; Hollister, E. B.; Lesniewski, R. A.; Oakley, B. B.; Parks, D. H.; Robinson, C. J.; Sahl, J. W.; Stres, B.; Thallinger, G. G.; Van Horn, D. J.; Weber, C. F., Introducing mothur: open-source, platformindependent, community-supported software for describing and comparing microbial communities. Applied and Environmental Microbiology 2009, 75 (23), 7537-7541. DOI: 10.1128/AEM.01541-09.

23. Villano, M.; Scardala, S.; Aulenta, F.; Majone, M., Carbon and nitrogen removal and enhanced methane production in a microbial electrolysis cell. Bioresource Technology 2013, 130, 366-371. DOI: 10.1016/j.biortech.2012.11.080.

24. Zeppilli, M.; Villano, M.; Aulenta, F.; Lampis, S.; Vallini, G.; Majone, M., Effect of the anode feeding composition on the performance of a continuous-flow methane-producing microbial electrolysis cell. Environmental Science and Pollution Research 2014, 22 (10), 73497360. DOI: 10.1007/s11356-014-3158-3.

25. Freguia, S.; Rabaey, K.; Yuan, Z.; Keller, J., Electron and carbon balances in microbial fuel cells reveal temporary bacterial storage behavior during electricity generation. Environmental Science \& Technology 2007, 41 (8), 2915-2921. DOI: 10.1021/es062611i.

26. Zhen, G.; Kobayashi, T.; Lu, X.; Xu, K., Understanding methane bioelectrosynthesis from carbon dioxide in a two-chamber microbial electrolysis cells (MECs) containing a carbon biocathode. Bioresource Technology 2015, 186, 141-148. DOI: 10.1016/j.biortech.2015.03.064.

27. Xafenias, N.; Mapelli, V., Performance and bacterial enrichment of bioelectrochemical systems during methane and acetate production. International Journal of Hydrogen Energy 2014, 39 (36), 21864-21875. DOI: 10.1016/j.ijhydene.2014.05.038. 
28. Fu, Q.; Kuramochi, Y.; Fukushima, N.; Maeda, H.; Sato, K.; Kobayashi, H., Bioelectrochemical analyses of the development of a thermophilic biocathode catalyzing electromethanogenesis. Environmental Science \& Technology 2015, 49 (2), 1225-1232. DOI: $10.1021 /$ es5052233.

29. Kobayashi, H.; Saito, N.; Fu, Q.; Kawaguchi, H.; Vilcaez, J.; Wakayama, T.; Maeda, H.; Sato, K., Bio-electrochemical property and phylogenetic diversity of microbial communities associated with bioelectrodes of an electromethanogenic reactor. Journal of Bioscience and Bioengineering 2013, 116 (1), 114-117. DOI: 10.1016/j.jbiosc.2013.01.001.

30. Rabaey, K.; Boon, N.; Siciliano, S. D.; Verhaege, M.; Verstraete, W., Biofuel cells select for microbial consortia that self-mediate electron transfer. Applied and Environmental Microbiology 2004, 70 (9), 5373-5382. DOI: 10.1128/AEM.70.9.5373-5382.2004.

31. Geelhoed, J. S.; Stams, A. J. M., Electricity-assisted biological hydrogen production from acetate by Geobacter sulfurreducens. Environmental Science \& Technology 2011, 45 (2), 815820. DOI: $10.1021 /$ es102842p.

32. Aulenta, F.; Catapano, L.; Snip, L.; Villano, M.; Majone, M., Linking bacterial metabolism to graphite cathodes: electrochemical insights into the $\mathrm{H}_{2}$-producing capability of Desulfovibrio sp. ChemSusChem 2012, 5 (6), 1080-1085. DOI: 10.1002/cssc.201100720.

33. Daghio, M.; Vaiopoulou, E.; Patil, S. A.; Suárez-Suárez, A.; Head, I. M.; Franzetti, A.; Rabaey, K., Anodes stimulate anaerobic toluene degradation via sulfur cycling in marine sediments. Applied and Environmental Microbiology 2016, 82 (1), 297-307. DOI: 10.1128/AEM.02250-15. 
34. Poulsen, M.; Schwab, C.; Borg Jensen, B.; Engberg, R. M.; Spang, A.; Canibe, N.; Højberg, O.; Milinovich, G.; Fragner, L.; Schleper, C.; Weckwerth, W.; Lund, P.; Schramm, A.; Urich, T., Methylotrophic methanogenic Thermoplasmata implicated in reduced methane emissions from bovine rumen. Nat Commun 2013, 4, 1428. DOI: 10.1038/ncomms2432.

35. Jiang, B.; Parshina, S. N.; van Doesburg, W.; Lomans, B. P.; Stams, A. J. M., Methanomethylovorans thermophila sp. nov., a thermophilic, methylotrophic methanogen from an anaerobic reactor fed with methanol. International Journal of Systematic and Evolutionary Microbiology 2005, 55 (6), 2465-2470. DOI: 10.1099/ijs.0.63818-0.

36. Mochimaru, H.; Tamaki, H.; Hanada, S.; Imachi, H.; Nakamura, K.; Sakata, S.; Kamagata, Y., Methanolobus profundi sp. nov., a methylotrophic methanogen isolated from deep subsurface sediments in a natural gas field. International Journal of Systematic and Evolutionary Microbiology 2009, 59 (4), 714-718. DOI: 10.1099/ijs.0.001677-0.

37. Dykstra, C. M.; Pavlostathis, S. G., Methanogenic biocathode microbial community development and the role of Bacteria. Environmental Science \& Technology 2017, 51 (9), 53065316. DOI: 10.1021/acs.est.6b04112. 
Table 1. Performance of $\mathrm{BC} 1$ and $\mathrm{BC} 2$ (average \pm standard deviation). Abbreviations: $\mathrm{BC}$ : biocathode; CE: coulombic efficiency; Rcat:cathodic methane recovery; EEe: energy recovery related to electrical input; EEs: energy recovery related to substrate; EEe+s: energy recovery related to substrate and electrical input.

\begin{tabular}{|c|c|c|}
\hline Parameter & BC1 & BC2 \\
\hline $\mathrm{CH}_{4}$ production $\left(\mathrm{m}^{3} \mathrm{~m}^{-3} \mathrm{~d}^{-1}\right)$ & $0.23 \pm 0.01$ & $0.22 \pm 0.05$ \\
\hline CE $(\%)$ & $33 \pm 10$ & $25 \pm 12$ \\
\hline $\mathrm{R}_{\text {cat }}(\%)$ & $65 \pm 8$ & $79 \pm 17$ \\
\hline $\mathrm{EE}_{\mathrm{e}}(\%)$ & $57 \pm 17$ & $61 \pm 16$ \\
\hline $\mathrm{EE}_{\mathrm{s}}(\%)$ & $23 \pm 6$ & $54 \pm 34$ \\
\hline $\mathrm{EE}_{\mathrm{e}+\mathrm{s}}(\%)$ & $17 \pm 2$ & $33 \pm 18$ \\
\hline
\end{tabular}




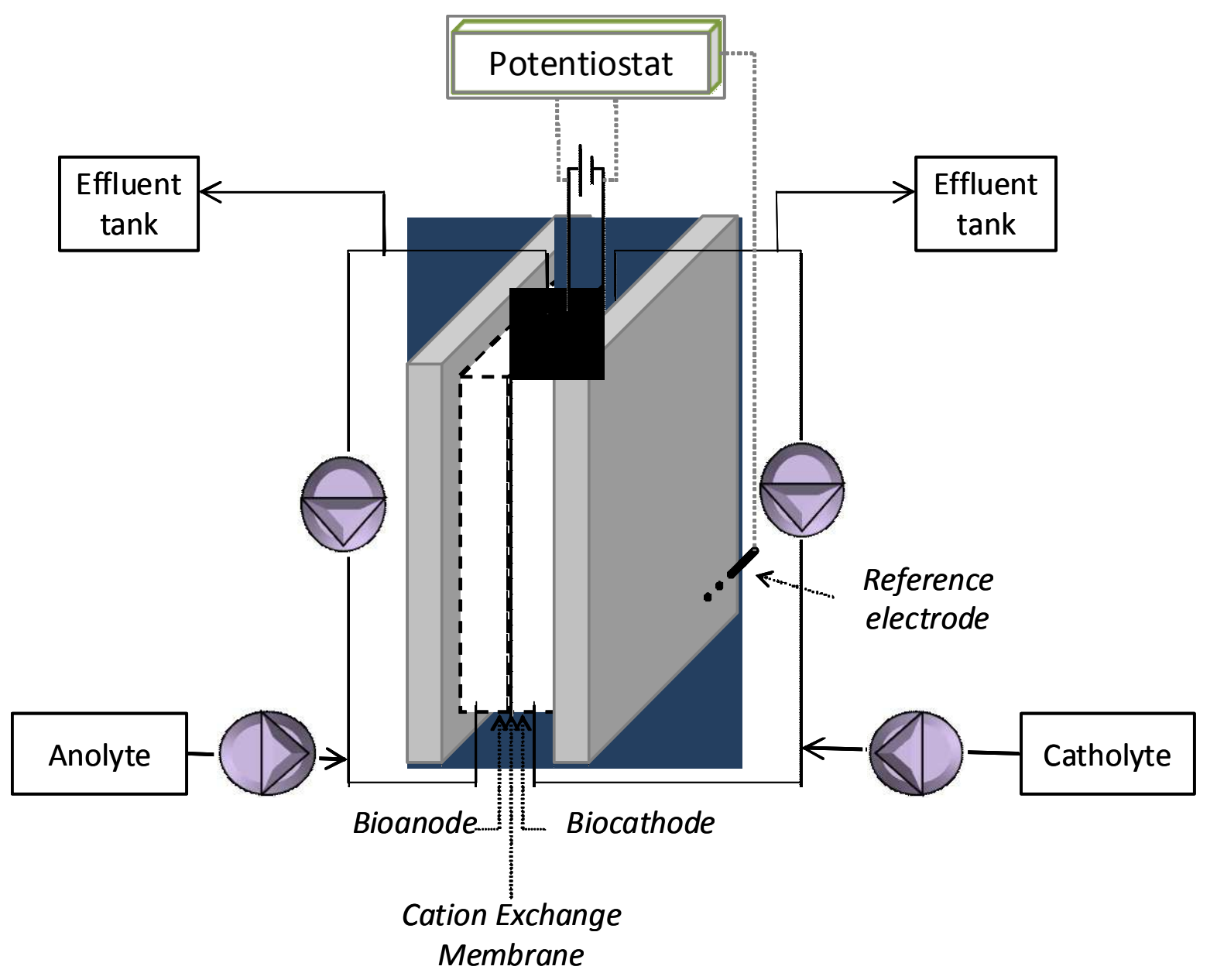

Figure 1. Scheme of the reactor set-up. 


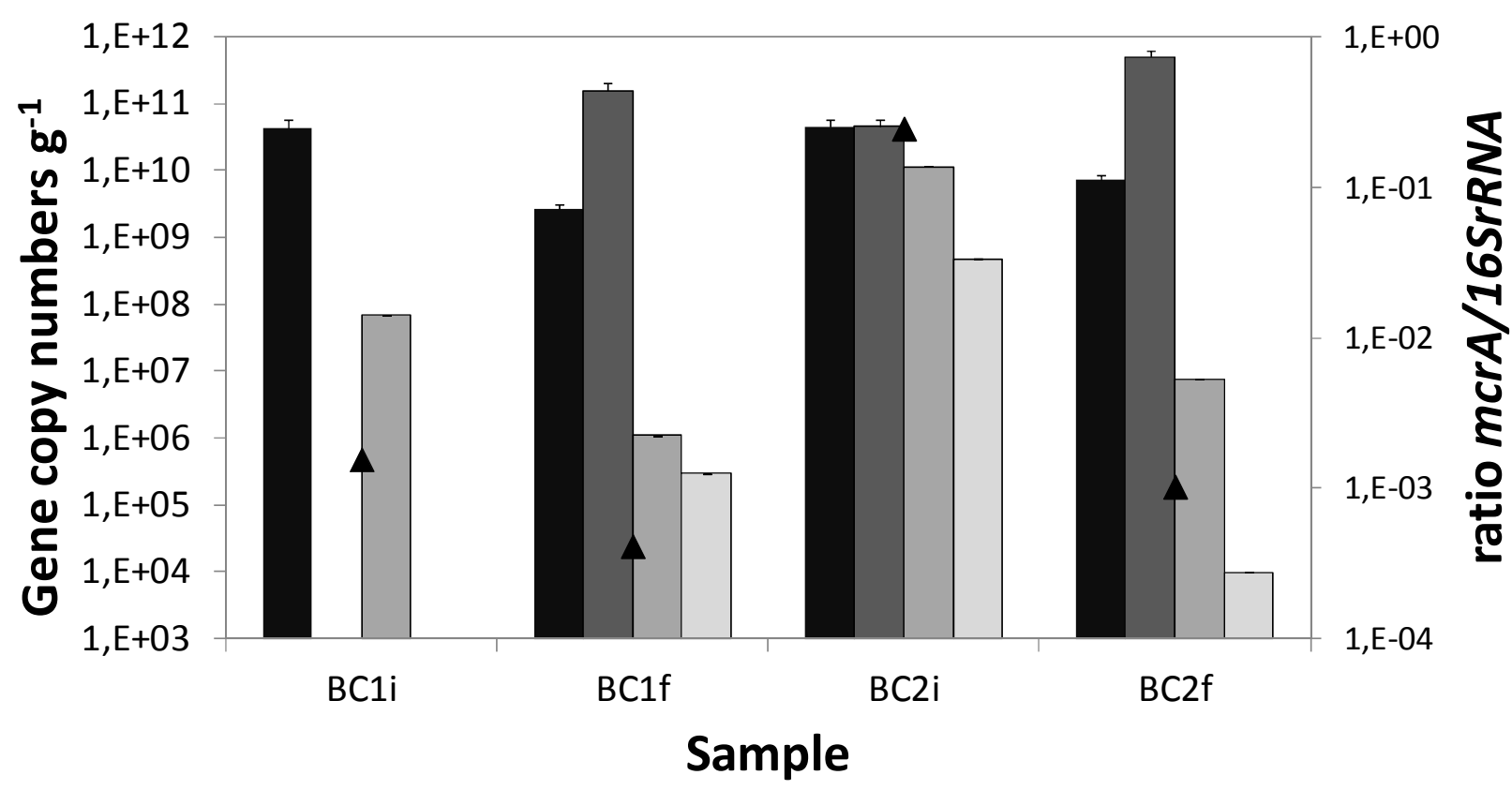

Figure 2. Gene copy numbers and transcripts of $16 S$ rRNA and mcrA genes from initial inoculum of $\mathrm{BC} 1$ and $\mathrm{BC} 2$ (i) and the final enrichment on each biocathode (f). $16 S$ rRNA-DNA, in black bars; $16 S r R N A$-cDNA, in dark grey bars; $m c r A$-DNA, in medium grey bars; $m c r A$ cDNA, in light grey bars; ratio $m c r A / 16 S r R N A$, in triangle. 
a)

b)

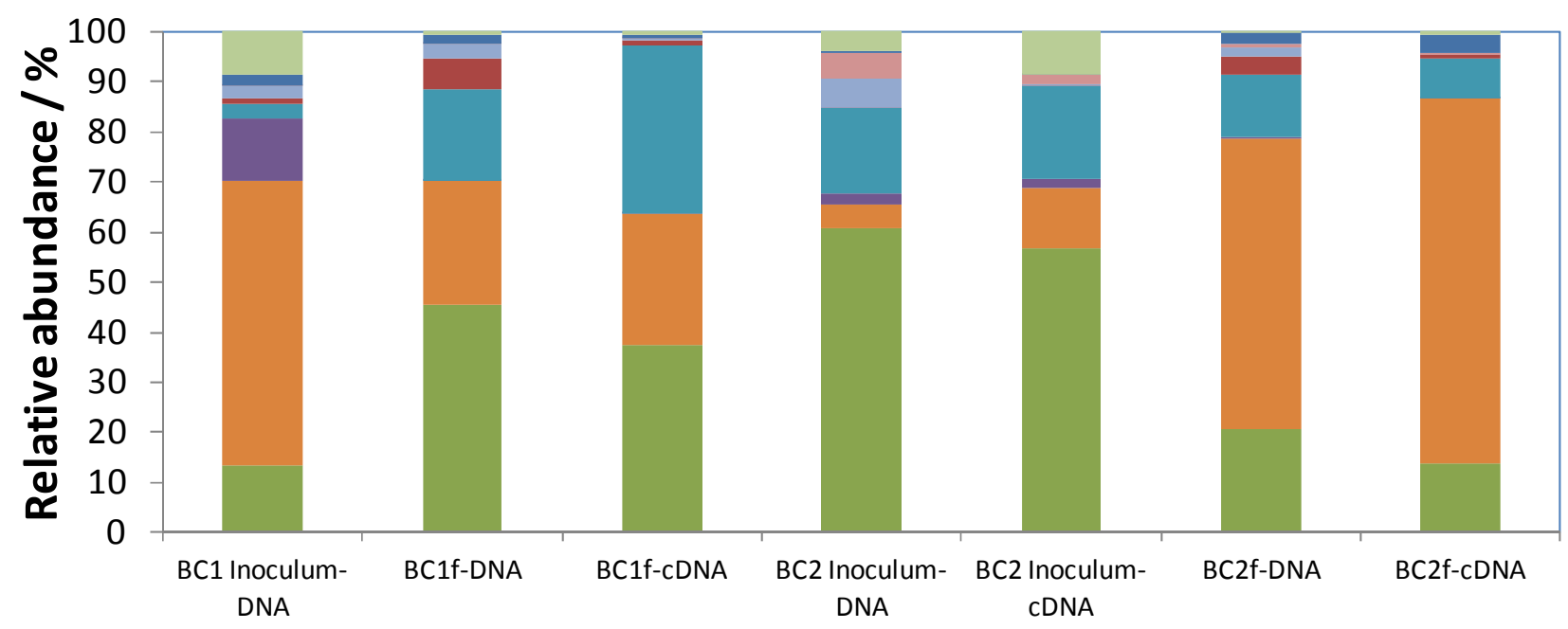

$\begin{array}{lll}\text { Bacteroidetes } & \text { Proteobacteria } & \text { Chloroflexi } \\ \text { Firmicutes } & \text { Actinobacteria } & \text { Spirochaetes } \\ \text { Synergistetes } & \text { Others } & \text { Unclassified }\end{array}$

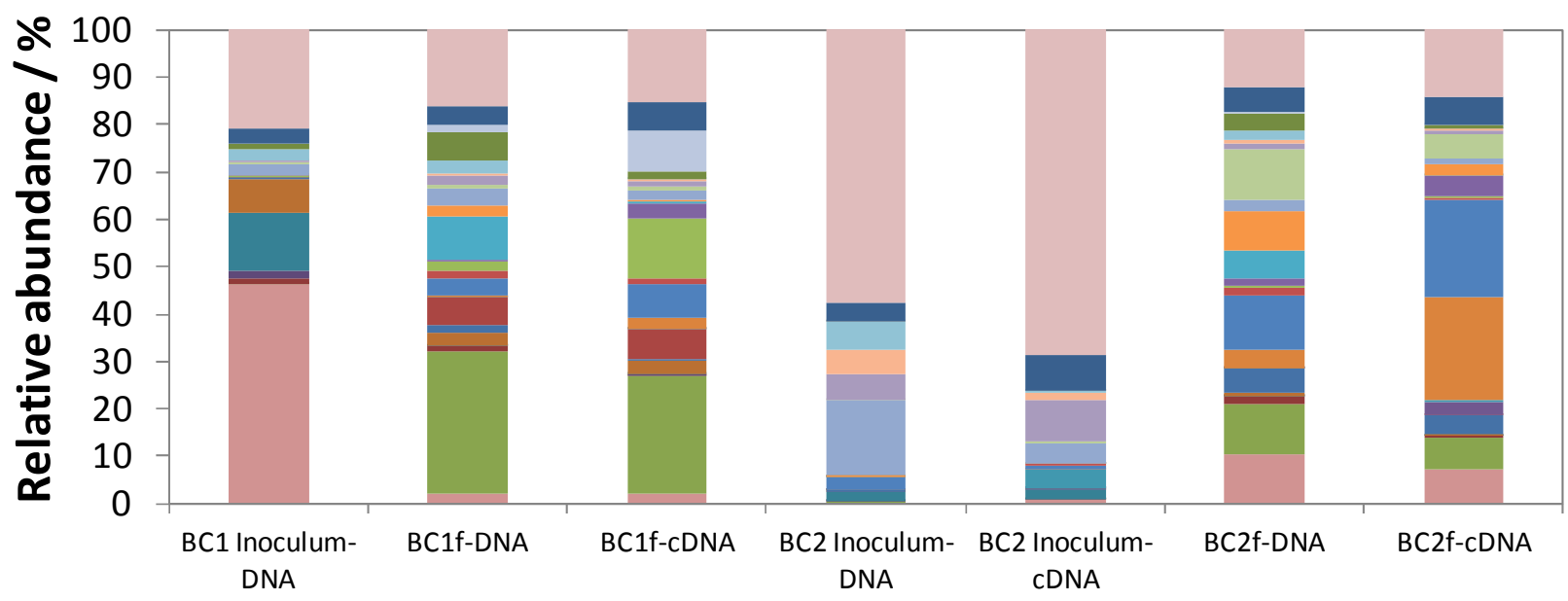

Syntrophomonadaceae

Synergistaceae

- Porphyromonadaceae

- Geobacteraceae

Desulfovibrionaceae

- Deferribacteraceae

- Campylobacteraceae

- Acholeplasmataceae 
Figure 3. Taxonomic assignment of sequencing reads from Eubacterial community of the inoculum of $\mathrm{BC} 1$ and $\mathrm{BC} 2$ and the final sample of each cathode for DNA (total population) and cDNA (active populations), at a) phylum b) family levels. Relative abundance was defined as the number of reads (sequences) affiliated with any given taxon divided by the total number of reads per sample. Phylogenetic groups with a relative abundance lower than $1 \%$ were categorized as "others". 
Figure 4. Taxonomic assignment of sequencing reads from Archaeal community of the inoculum of $\mathrm{BC} 1$ and $\mathrm{BC} 2$ and the final sample of each cathode for DNA (total population) and cDNA (active populations) at family level. Relative abundance was defined as the number of reads (sequences) affiliated with any given taxon divided by the total number of reads per sample. Phylogenetic groups with a relative abundance lower than $1 \%$ were categorized as "others". 
TABLE OF CONTENT (TOC) GRAPHIC
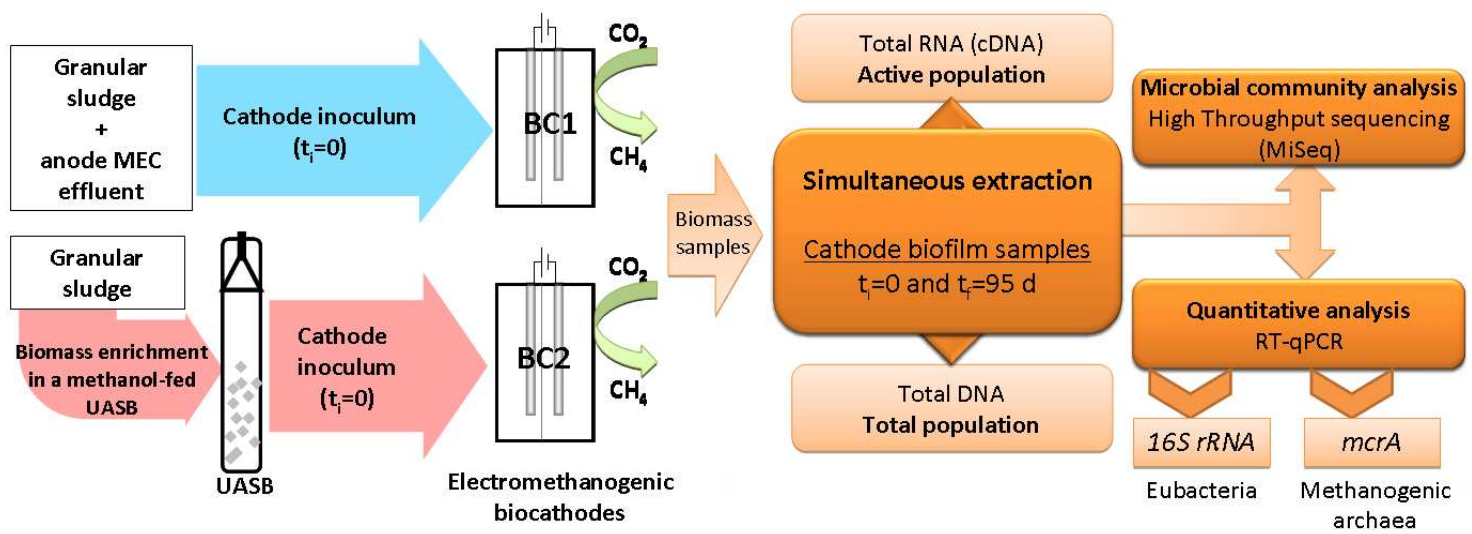

SYNOPSIS. Microbial electrolysis cells (MEC) with electromethanogenic biocathodes were assessed as a technology for upgrading the biogas produced in anaerobic digesters. 


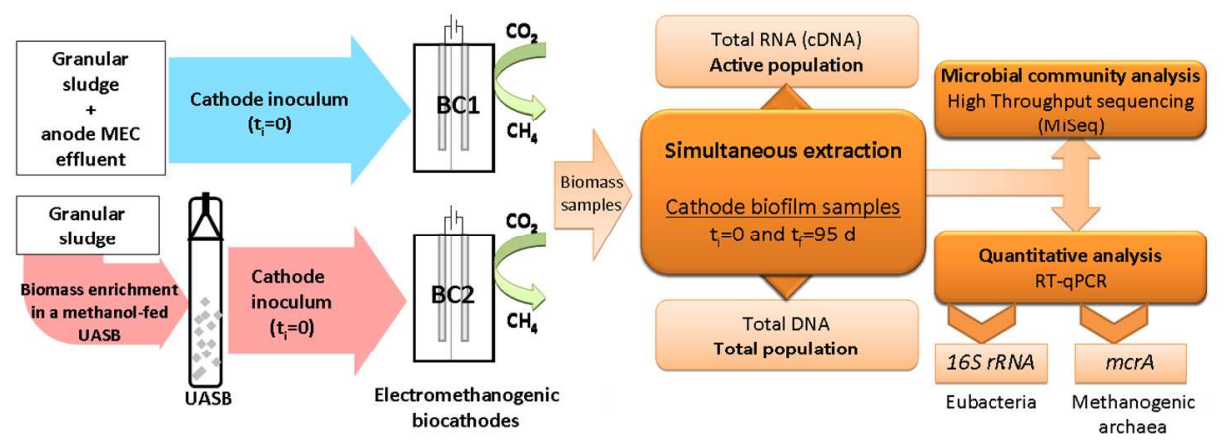

Graphical abstract

$394 \times 141 \mathrm{~mm}(96 \times 96 \mathrm{DPI})$ 